Rigor mortis well marked. Thorax: Both lungs em. physematous at upper lobes; bases congested; adhesions from old pleurisy on left side. Heart empty, somewhat flabby, valves and vessels good; no atheroma. Abdomen : Small and large intestines distended with gas; very little feces in small intestine. The large intestine from the ileoceeal valve to splenic flexure full of freces of soft consistence; below this point no freces, but gut was full of gas; no general peritonitis. Just to the right of the splenic flexure the colon was adherent to the greater curvature of the stomach, and at the outer border of the colon was a small perforation the size of a goosequil, through which fæces were oozing into the peritoneal cavity. At this point the bowel colon way constricted by the adhesions binding it to the stomach. On removing the stomach and colon a large ulcer on the greater curvature of the stomach was seen to open into the colon, one inch and a half in diameter; old. The edges had a reddened, granulating look, as if partially contracting under a healing process. The edges were not much thickened, and there was no evidence of cancerous deposit or growth. No glandular enlargement was discovered, and the rest of the stomach and intestines seemed healthy. Liver healthy; no gallstones; bladder full of bile. Kidneys : Perinephritic fat very abundant and adherent; capsules peeled well; numerous cysts in both, from the size of a pea to that of a pigeon's egg. Cortex narrow, and not well marked. Spleen healthy, decomposing; bladder empty; prostate large. The post-mortem examination cleared up the puzzle; the stercoraceous vomiting was a natural relief per os, and not per anum. Surgical interference would not have given relief, but probably the reverse; and had not the colon given way into the peritoneum, softened probably by the gastric juice, the man might still have been alive, and the pazzle more difficult of solution than ever.

\section{ANCOATS HOSPITAL, MANCHESTER.}

A CASE OF ANKYLOSIS FOLLOWING EXCISION OF THE ELBOW-JOINT, TREATED EY HYPNOTIC SUGGESTION.

(Under the care of Mr. HARE.)

MCCH has been written of late on the use of hypnotism in medical practice, and it has been somewhat extensively tried in various conditions widely different in character. The most beneficial results have been obtained in morbid states of the nervous system; but what will be the ultimate verdict of unbiased investigation upon its usefulness it is difficult to say. This case is a further contribution to those in surgery where its employment has been found of service, for such are, as a rule, difficult to treat satisfactorily without the use of chloroform or other anæsthetic. For the account of the case we are indebted to Mr. H. T. Mursell, senior resident surgeon.

E. Son August 22nd, 1890, under the care of Professor Hare, suffering from ankylosis of the elbow-joint of long. standing. Prior to admission various methods of treat ment had been tried without success. On examination some thickening and enlargement of the joint structures were made out, but nothing of a very marked character. The limb was slightly flexed, and as regards flexion, there was almost absolute immobility; pronation and supination were also impaired, but to a less extent. Any forcible attempt at movement caused great pain. Under an ancesthetic there was still difficulty in obtaining movement, and as the limb was practically useless in its present position excision of the joint was decided upon, the operation being performed by Professor Hare on Aug. 25th. All the bony surfaces entering into the forma tion of the joint were removed, and on examination an exostosis growing from the articular surface of the head of the radius was found to be the cause of the condition. The limb was dressed antiseptically, but unfortunately did not heal by first intention. Passive movement was commenced as early as was deemed advisable, but the highly neurotic temperament of the patient rendered the efficient carrying nut of this part of the treatment extremely difficult. Citimately, in spite of everything, the limb became immobile at the site of the elbow joint, and almost in the extended position.
Uader chlorolorm the limb was freely moved and adhesions broken down, but the patient was nut amenable to passive movements, and ankylosis in the extended pusition again occurred.

With Professor Hare's sanction, Mr. Mursell tried what could be effected by hypnotic suggestion. The girl was easily hypnotised by causing her to gaze steadily at a retinoscopy mirror held in her hand, by the verbal suggestion of sleep, and by pressure on the frontal prominences. The patient responded to almost any suggestion which was made, and anresthesia could be readily induced in any part of the body by verbal suggestion. She was told that she could move the affected arm without pain or difficulty of any sort, and readily bent the elbow sufficiently to touch the mouth with the hand when commanded to do so. She was told that this free movement would remain and be quite painless after she woke up. This post-hypnotic suggestion proved to be still existent and effective two or three days later. Movement was still somewhat imperfect, and she was again hypnotised about a week later. This time the same method was employed, and by verbal suggestion the patient was able readily to touch the back of the head with the hand, and to perform flexion, supination, and pronation withont any difficulty. She was assured this condition would remain permanently when she awoke. From this time she had no difficulty in using the affected arm, and completely regained the efficient use of the limb. The patient was discharged cured on Nov. 18th, 1890.

Remarks by Mr. MURSELL. - The most rational explanation of the treatment is probably that the immobility following the operation was due partly to fibrous adhesion between the ends of the bones, a comparatively small portion of the humerus having been removed, that any attempt at movement caused pain, and thus the patient was afraid to make the attempt, and there was a mental impression of inability to move the limb By suggestion pain and the mental impression of inability to move the limb were removed, and the movements executed in consequence of this were sufficient to break down and overcome the fibrous adhesions. The unusual method of treatment and the success attending it must be my excuse for publishing a single case. I am indebted to professor Hare for permission to do so.

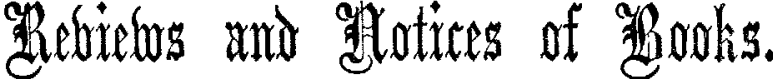

Hypnotic Suggestion. By Augustus Nicoll, M.B. Edin. London: Henry Renshaw. 1891.

The Dangers of Hypnotism. By ST. ClaIR THonson, M.D. Lond. (Reprinted from the Westminster Review. THE stream of literature dealing with hypnotisn shows no sign of slackening. It is not surprising that a subject of great intrinsic interest, and one which touches on the one hand psychology and on the other pathology and therapeutics, should invite the attention of many minds and provoke active controversy. Dr. Nicoll's short work is a plea for hypnotism by a convinced believer in its great therapeutic utility. He adopts the dictum of the Nancy school, Tout est dans la suggestion, and regards the hypnotie slumber as important only in heightening the susceptibility to suggestion. This is the doctrine of Bernheim and Liébeault, and represents a position that seems to command increasing support. Dr. Nicoll gives a short résumé of the evidence showing the power of suggestion and quotes largely from Dr. Luys and other authorities. He has nothing new to tell us, however, and mee is most objections by the simple denial that they have any solid foundation in fact. He writes in a way that seems to imply that he considers the only value of drugs to lie in the fact that they "suggest" the idea of cure to the patient. and quotes with approbation Oliver Wendell Holmes's jocular remark that, "Were it not for the happy illusion that his useless or even deleterious drugs were doing good service, many a practitioner would give up his calling." If this view were correct, one substance-say, aqua purawould be sufficient, if skilfully handled, to "suggest" the 